\title{
Effect of pH on the Hydrolytic Kinetics of Gamma-Glutamyl Transferase from Bacillus subtilis
}

\author{
Sharath Balakrishna and Asmita Prabhune \\ Division of Biochemical Sciences, Room No. 1846, National Chemical Laboratory, Dr. Homi Bhabha Road, Pune 411008, India \\ Correspondence should be addressed to Asmita Prabhune; aa.prabhune@ncl.res.in
}

Received 17 November 2013; Accepted 18 January 2014; Published 24 February 2014

Academic Editors: D. Benke, J. C. Gómez-Fernández, and A. Surguchov

Copyright ( 2014 S. Balakrishna and A. Prabhune. This is an open access article distributed under the Creative Commons Attribution License, which permits unrestricted use, distribution, and reproduction in any medium, provided the original work is properly cited.

\begin{abstract}
The effect of $\mathrm{pH}$ on the steady state kinetics of gamma-glutamyl transferase (GGT) from Bacillus subtilis was examined using glutamyl-(3-carboxyl)-4-nitroanilide as the chromogenic reporter substrate. The enzyme was active in the $\mathrm{pH}$ range $7.0-11.0$ with the optimum activity at $\mathrm{pH}$ 11.0. We noticed a $\mathrm{pH}$ dependent transformation in the nature of substrate consumption kinetics. The substrate saturation curves were hyperbolic in the $\mathrm{pH}$ range 7.0-9.0 but changed into sigmoid form at $\mathrm{pH} 10.0$ and 11.0. Hill's coefficients were $>1$. We also analysed the effect of $\mathrm{pH}$ on the structure of the enzyme. The circular dichroism spectra of the enzyme sample at pH 9.0 and 11.0 were coincidental in both far and near UV regions indicating conservation of the secondary and tertiary structures, respectively. The molecular weight of the enzyme sample was the same in both $\mathrm{pH} 7.0$ and 11.0 indicating conservation of the quaternary structure. These results show that the kinetic transformation does not involve significant conformational changes. Cooperative binding of multiple substrate molecules may not be the basis for the sigmoid kinetics as only one substrate binding site has been noticed in the reported crystal structures of B. subtilis GGT.
\end{abstract}

\section{Introduction}

Gamma-glutamyl transferases (GGT) (E.C.2.2.3.2) are a family of highly conserved enzymes occurring in archaebacteria, eubacteria, fungi, protozoa, nematodes, plants, and mammals [1]. They catalyse the exogenous removal of the terminal $\gamma$ glutamyl moiety from amides or peptides and its subsequent transfer to water (hydrolysis) or an acceptor amine (transpeptidation) or a second substrate molecule (autotransfer). The acceptor amine can be a peptide or an amino acid with a free amino group. The three reactions are represented below:

$$
\begin{aligned}
& \gamma \text { GluCONHR }+\mathrm{H}_{2} \mathrm{O} \longleftrightarrow \mathrm{Glu}+\mathrm{RNH}_{2} \\
& \text { (Hydrolysis) } \\
& \gamma \mathrm{GluCONHR}^{1}+\mathrm{R}^{2} \mathrm{CONH}_{2} \longleftrightarrow \gamma \mathrm{GluCOR}^{2}+\mathrm{R}^{1} \mathrm{NH}_{2} \\
& \text { (Transpeptidation) } \\
& 2 \gamma \text { GluCONHR } \longleftrightarrow \gamma \text { Glu-GluCONHR }+\mathrm{RNH}_{2} \\
& \text { (Autotranspeptidation) }
\end{aligned}
$$

Mammalian GGTs are involved in xenobiotic detoxification [2] and homeostasis of glutathione [3]. Human GGT plays a role in pathologies like metastasis [4] and drug resistance of malignant cells [5], cardiovascular diseases [6], inflammation [7], and diabetes [8] and neurodegenerative diseases [9]. Plant GGTs are speculated to participate in the synthesis of flavour compounds [10]. There are indications that Bacillus subtilis GGT catalyses the degradation of capsular $\gamma$-polyglutamic acid [11] while its homologue in Bacillus anthracis (capD) mediates covalent anchorage of capsular $\gamma$-poly-D-glutamic acid to the cell wall [12]. In Helicobacter pylori and Neisseria meningitidis, GGT helps the bacterium to colonize the intestinal epithelium [13] and the brain [14], respectively. So far, no unifying function has been found to explain the strong conservation across the phylogenetic tree. We are interested in the structure-function relationships of GGT. We have crystallised B. subtilis GGT and determined its X-ray crystallographic structure [15]. In the present study, we explore the effect of $\mathrm{pH}$ on the steady state kinetics of $B$. subtilis GGT and show its unique properties. 


\section{Materials and Methods}

2.1.Chemicals. Glutamyl-(3-carboxyl)-4-nitroaniline ammonium salt was obtained from Fluka (Switzerland). All other reagents used were from Sigma Chemicals (USA).

2.2. Cloning and Expression of B. subtilis GGT. The GGT ORF was amplified from the genomic DNA of $B$. subtilis strain with the primers 5'ACG CGG CCA TGG TAA AGC CGC CCA AAA GCT3' (forward) and $3^{\prime}$ GTT TTT CTC GAG TTT ACG TTT TAA ATT GCC GAT5' (reverse). The primers append $5^{\prime}$ and $3^{\prime}$ termini of the amplicon with flanks bearing recognition sites for the restriction enzymes $\mathrm{NcoI}$ and XhoI, respectively. The amplicon was produced by 25 cycles of Taq DNA polymerase catalysed polymerase chain reaction. Each thermal cycle comprised of $30 \mathrm{~s}$ denaturation at $94^{\circ} \mathrm{C}, 30 \mathrm{~s}$ annealing at $50^{\circ} \mathrm{C}$ and $90 \mathrm{~s}$ extension at $72^{\circ} \mathrm{C}$. Both amplicon and pET26b (Novagen) plasmid DNA were digested with NcoI and XhoI and then ligated to generate pET28a-GGT construct. The construct substitutes the N-terminal signal peptide with $E$. coli specific equivalent and appends a Cterminal hexahistidine tag.

The construct was transformed into E. coli expression strain BL21 (Stratagene). For protein production, the cells were grown in LB medium supplemented with $30 \mu \mathrm{g} / \mathrm{mL}$ kanamycin. When $\mathrm{OD}_{600}$ reached 0.5 , the culture was induced by adding isopropyl-b-D-thiogalactopyranoside (IPTG) to a final concentration of $1 \mathrm{mM}$. Thereafter, the incubation was continued at $16^{\circ} \mathrm{C}$ overnight. The cells were pelleted by centrifugation at 6000 r.p.m. and stored at $-20^{\circ} \mathrm{C}$ till further use.

2.3. Purification of GGT. IPTG induced cell pellet was suspended in $20 \mathrm{mM}$ sodium phosphate buffer $\mathrm{pH} 7.0$ and $500 \mathrm{mM} \mathrm{NaCl}$ (buffer A) containing $20 \mathrm{mM}$ imidazole. The cell suspension was homogenised by two cycles of extrusion through French press at 1500 psi. The homogenate was clarified by centrifugation at 15000 r.p.m. for $1 \mathrm{hr}$ and filtered through $0.45 \mu$ membrane. The filtrate was loaded onto $1 \mathrm{~mL}$ HisTrap column (Amersham Biosciences) containing precharged high performance nickel sepharose, preequilibrated with buffer $A$ and washed with the same buffer till $\mathrm{OD}_{280}$ of the effluent reached the baseline. The bound protein was eluted with a linear gradient of $20-500 \mathrm{mM}$ imidazole contained in the binding buffer. The fractions corresponding to the single major peak were pooled and loaded onto Hi-Load Superdex S200 (Amersham Biosciences) column preequilibrated with $100 \mathrm{mM}$ tris $\mathrm{HCl} \mathrm{pH} 7.5$ and $100 \mathrm{mM}$ $\mathrm{NaCl}$. Pure GGT eluted as a single prominent peak and was confirmed by activity test and SDS-PAGE analysis. The protein was concentrated to $10 \mathrm{mg} / \mathrm{mL}$ over a $10 \mathrm{kDa}$ cutoff membrane (Pall) and preserved at $-20^{\circ} \mathrm{C}$.

2.4. Enzyme Assay. The enzyme was assayed by modified method of Suzuki et al. [16]. Briefly, $0.4 \mu \mathrm{g}$ of enzyme was incubated at $30^{\circ} \mathrm{C}$ for 5 mins with the ammonium salt of glutamyl-(3-carboxyl)-4-nitroaniline in $100 \mathrm{mM}$ buffer in a final volume of $100 \mu \mathrm{L}$. Buffers used were Tricine for $\mathrm{pH} 7.0-$ 9.0 and $N$-cyclohexyl-3-aminopropanesulfonic acid (CAPS) for $\mathrm{pH} 10.0-11.0$. The reaction was arrested with $900 \mu \mathrm{L}$ of $2 \mathrm{M}$ acetic acid and the absorbance measured at $410 \mathrm{~nm}$. Suitable blanks were used to correct for absorbance due to the substrate. One unit of enzyme was defined as $\mu$ moles of 3 carboxyl-4-nitroaniline formed in one minute. The assay was linear with respect to time of incubation.

2.5. Steady State Kinetics. Substrate saturation plots were prepared by measuring the reaction rates in a range of substrate concentrations. Concentrations were chosen to give a relatively even distribution of the data points. $K_{m}$ and $V_{\max }$ were determined by fitting the velocities to Michaelis-Menten equation by nonlinear regression method using Origin 6.1:

$$
v=V_{\max } \frac{[S]}{K_{m}+[S]} .
$$

For measurements made at $\mathrm{pH} 10.0$ and 11.0, the velocities were fitted by nonlinear regression to Hill's equation of the form:

$$
v=V_{\max } \frac{[S]^{h}}{K_{0.5}+[S]^{h}},
$$

where $v$ is the initial velocity, $V_{\max }$ is maximal velocity, $K_{m}$ and $K_{0.5}$ are the substrate concentrations for half maximal activity and $h$ is the measure of cooperativity between $n$ interacting sites.

2.6. Circular Dichroism (CD) Measurement. CD spectra were collected on a Jasco J-715 spectropolarimeter. Near and far UV CD spectra (200-250 nm) were collected with 0.1 and $1 \mathrm{mg} / \mathrm{mL}$ of the enzyme placed in a path length of 0.1 and $1 \mathrm{~cm}$, respectively. The final spectrum was an average of 5 accumulations measured at a rate of $100 \mathrm{~nm} / \mathrm{min}$ at $1 \mathrm{~nm}$ resolution.

2.7. Molecular Weight Estimation by Size Exclusion Chromatography. 1x $100 \mathrm{~cm}$ Sephacryl S 200 was equilibrated with $150 \mathrm{mM} \mathrm{NaCl}$ in $50 \mathrm{mM} \mathrm{Na}-\mathrm{K}$ phosphate buffer $\mathrm{pH}$ 7.0. The elution volume of blue dextran was considered as the void volume of the packed column. The column was calibrated by passing cytochrome C (12000 Da), carbonic anhydrase $(24000 \mathrm{Da})$, bovine serum albumin $(66000 \mathrm{Da})$, alcohol dehydrogenase (15000 Da), and beta-amylase (200000 Da). A calibration curve was constructed by plotting logarithm of the molecular weight of the individual marker against the ratio of the void (vo) and respective elution volumes (ve). A sample of B. subtilis GGT was passed through the calibrated column and its ve/vo ratio was used to calculate the molecular weight from the calibration curve. The column was then equilibrated with $100 \mathrm{mM}$ CAPS buffer $\mathrm{pH} 11.0$ and $150 \mathrm{mM} \mathrm{NaCl}$ and used to estimate the molecular weight of B. subtilis GGT as before.

2.8. Reversibility Study. A sample of the enzyme was incubated in $50 \mathrm{mM}$ CAPS buffer $\mathrm{pH} 11.0$ and $150 \mathrm{mM} \mathrm{NaCl}$ for 
$48 \mathrm{hrs}$ at $6^{\circ} \mathrm{C}$. The sample was then cleaned by dialysis against $100 \mathrm{mM}$ tris $\mathrm{HCl}$ buffer $\mathrm{pH} 7.5$ and $100 \mathrm{mM} \mathrm{NaCl}$.

2.9. Thermodynamic Analysis. The value of $k_{\mathrm{cat}}$ for the respective reaction was determined at $20,30,40$, and $50^{\circ} \mathrm{C}$. Arrhenius plot was used to calculate the activation energy. The data were fitted by linear regression to the equation:

$$
\ln k_{\mathrm{cat}}=-\frac{E_{a}}{R T}+\ln A,
$$

where $E_{a}$ is the activation energy, $R$ is the gas constant, $T$ is the absolute temperature, and $A$ is the frequency of collision. The slop of this plot is equal to $-E_{a} / R$.

Eyring's plot was used for the determination of enthalpy and entropy of activation. The data were fitted by linear regression to the equation:

$$
\ln \frac{k_{\mathrm{cat}}}{T}=\ln \frac{k_{B}}{h}+\frac{\Delta S^{\ddagger}}{R}-\frac{\Delta H^{\ddagger}}{R T},
$$

where $h$ is Planck's constant, $k_{B}$ is Boltzmann's constant, $R$ is gas constant, and $T$ is absolute temperature. From the plot, $\Delta H^{\ddagger}$ was calculated from the slope $\left(=-\Delta H^{\ddagger} / R\right)$ and $\Delta S^{\ddagger}$ from the $y$-axis intercept. Free energy of activation $\left(\Delta G^{\ddagger}\right)$ was calculated from the equation:

$$
\Delta G^{\ddagger}=\Delta H^{\ddagger}-T \Delta S^{\ddagger} .
$$

\section{Results}

3.1. Enzyme Preparation. B. subtilis GGT is expressed as single polypeptide precursor which undergoes posttranslational, intramolecular, and autocatalytic cleavage to produce a heterodimer [17]. The 2 polypeptide chains of the mature heterodimer weigh 45 and $22 \mathrm{KDa}$ (Supplemental Figure 1 available online at http://dx.doi.org/10.1155/2014/216270). Expression of the active enzyme was temperature dependent. Induction of mid-log cultures at $30^{\circ} \mathrm{C}$ resulted in the formation of unprocessed precursor. Fully processed, heterodimeric enzyme was produced when the cultures were induced at $16^{\circ} \mathrm{C}$.

3.2. $K_{m}$ and $p H$ Optimum. The kinetics of GGT catalysed hydrolysis was studied with $\gamma$-glutamyl-(3-carboxyl)-4nitroaniline as the substrate. The enzyme was active between $\mathrm{pH} 7.0$ and 11.0. The shape of the $\mathrm{pH}$ titration curve and the optimum condition depended on the amount of substrate used in the assay. The optimum was at $\mathrm{pH} 9.0$ when the assay used lower substrate concentration $(2 \mathrm{mM})$. And, the optimum was at $\mathrm{pH} 11.0$ when higher substrate concentration $(64 \mathrm{mM})$ was used (Figure 1). $K_{m}$ was found to be $25.9 \pm$

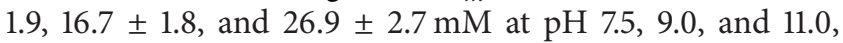
respectively. It was earlier reported to be $10.0 \mathrm{mM}$ at $\mathrm{pH} 9.0$ [18]. Thus, $\mathrm{pH}$ has negligible effect on the substrate affinity between pH 7.0 and 11.0. Among GGTs, the $K_{m}$ of B. subtilis GGT is unusually high. The reported $K_{m}$ values of other GGTs are mostly in micromolar concentrations: $68 \mu \mathrm{M}$ in $E$. coli GGT [16], $12 \mu \mathrm{M}$ in H. pylori GGT [19], $7 \mu \mathrm{M}$ in human GGT [20], $5 \mu \mathrm{M}$ in rat [21], $2 \mathrm{mM}$ in rabbit GGT [22], and $1.6 \mathrm{mM}$ in porcine GGT [23].

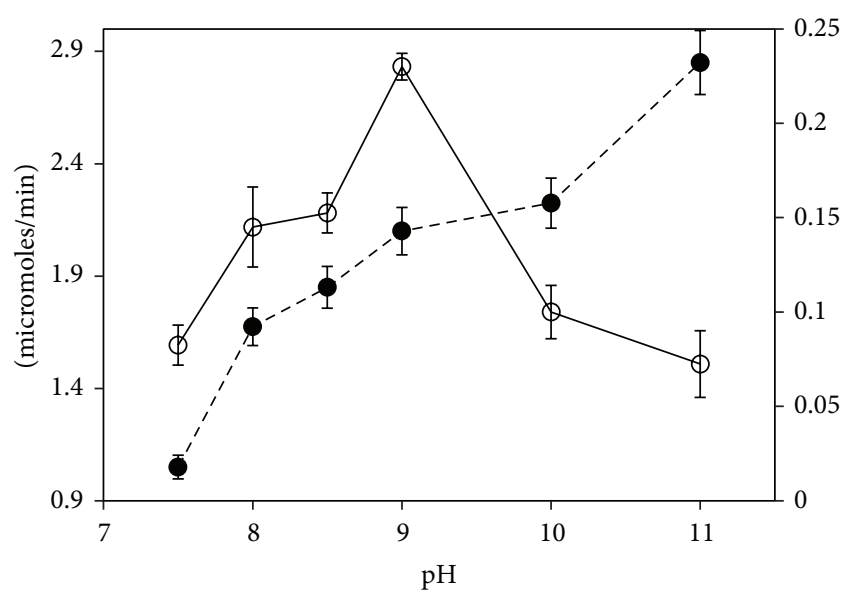

FIGURE 1: Effect of $\mathrm{pH}$ on B. subtilis GGT catalysed hydrolysis. Standard assay reactions were performed with either $2 \mathrm{mM}(\mathrm{O})$ or $64 \mathrm{mM}(\bullet) \gamma$-Glutamyl-(3-carboxyl)-4-nitroaniline.

3.3. Kinetic Transformation. Between $\mathrm{pH} 7.0$ and 9.0, the substrate saturation kinetics follows the standard MichaelisMenten form producing a hyperbolic response. However, at $\mathrm{pH} 10.0$ and 11.0, the substrate saturation curves were of sigmoid form (Figure 2). Standard deviation was higher ( $>10 \%)$ and adjusted coefficient of determination $\left(R^{2}\right)$ was relatively lower when the data was fitted to hyperbolic curve. Better fit was obtained with Hill's equation (see supplementary Table 1 for details). The Hill's coefficient $(h)$ was $1.6 \pm 0.5$ in $\mathrm{pH}$ 10.0 and $2.1 \pm 0.4$ at $\mathrm{pH}$ 11.0. Enzyme samples incubated at $\mathrm{pH} 11.0$ for $\sim 48$ hours produced hyperbolic saturation curves when assayed at $\mathrm{pH}$ 9.0. This indicates that the kinetic transformation between hyperbolic and sigmoid forms is reversible and does not involve any permanent changes in the enzyme.

3.4. Effect of $\mathrm{pH}$ on Structure. The influence of $\mathrm{pH}$ on the structure of the enzyme was analysed to determine if any changes accompanied the kinetic transformation. Potential changes in the secondary and tertiary structures were analysed by CD spectroscopy. Absorbance in the far UV (200-250 nm) is mostly due to backbone amide bonds and therefore spectral changes in this region represent alterations in the secondary structure [24]. Aromatic residues (Trp, Tyr, and Phe) absorb most of the UV in the near region (250$300 \mathrm{~nm}$ ); spectral changes in this region therefore are due to alterations in the tertiary structure [24]. CD spectra of $B$. subtilis GGT were collected in both far and near UV regions using samples present in $\mathrm{pH} 7.0$ and 11.0 buffers. The spectra produced by samples in $\mathrm{pH} 7.0$ and 11.0 were coincidental in both the UV regions (Supplemental Figure 2).

We then examined the effect of $\mathrm{pH}$ on the oligomeric state of the enzyme sample. The native molecular weight of the sample was analysed by gel-filtration method. The elution profiles in both $\mathrm{pH} 7.0$ and 11.0 were coincidental and corresponded to a molecular weight of $66 \mathrm{KDa}$ on the calibration curve (Supplemental Figure 3). Conservation of 


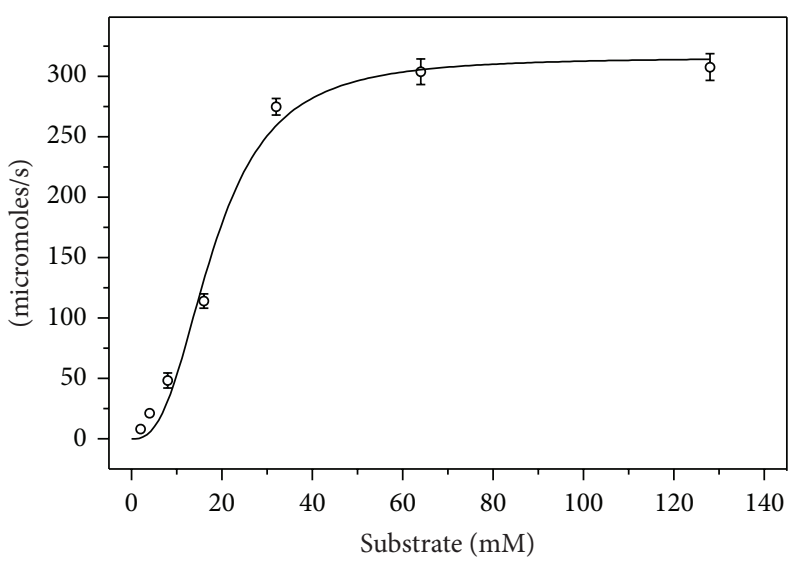

(a)

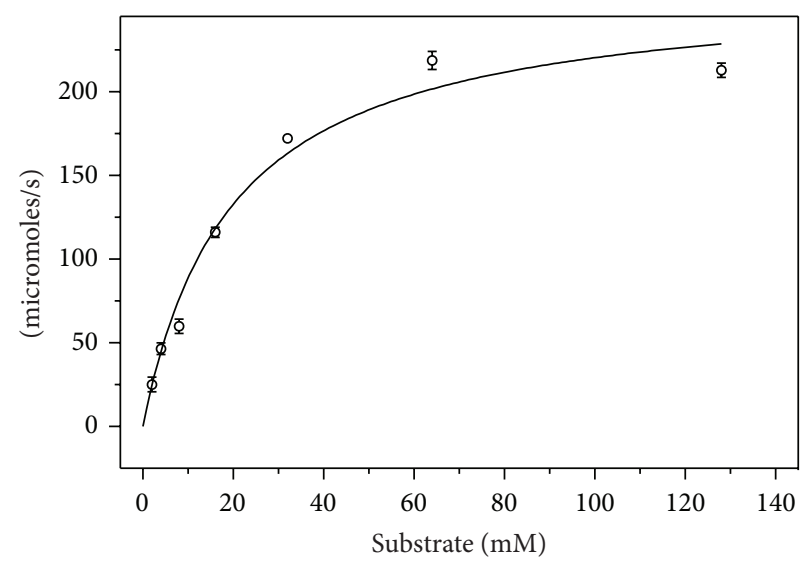

(b)

FIGURE 2: Effect of $\mathrm{pH}$ on the nature of saturation curve for B. subtilis GGT catalysed hydrolysis of $\gamma$-Glutamyl-(3-carboxyl)-4-nitroaniline. (a) and (b) represent substrate saturation curves at $\mathrm{pH} 9.0$ and $\mathrm{pH} 11.0$, respectively.

TABLE 1: Effect of $\mathrm{pH}$ on the thermodynamic parameters for the hydrolysis of $\gamma$-Glutamyl-(3-carboxyl)-4-nitroaniline.

\begin{tabular}{|c|c|c|c|c|}
\hline $\mathrm{pH}$ & $\begin{array}{l}\text { Activation energy } \\
\qquad\left(E_{a}\right) \\
\mathrm{KJ} / \mathrm{mol}\end{array}$ & $\begin{array}{c}\text { Activation enthalpy } \\
\left(\Delta H^{\ddagger}\right) \\
\mathrm{KJ} / \mathrm{mol}\end{array}$ & $\begin{array}{c}\text { Activation entropy } \\
\left(\Delta S^{\ddagger}\right) \\
\mathrm{J} / \mathrm{mol} \mathrm{K}\end{array}$ & $\begin{array}{c}\text { Free energy of activation } \\
\qquad\left(\Delta G^{\ddagger}\right) \\
\mathrm{KJ} / \mathrm{mol}\end{array}$ \\
\hline 7.5 & 23.9 & 21.6 & -147.7 & 65.6 \\
\hline 11.0 & 27.9 & 25.4 & -106.1 & 57.1 \\
\hline
\end{tabular}

the molecular weight indicates that the sample does not undergo oligomerization at higher $\mathrm{pH}$.

3.5. Thermodynamics of Hydrolysis across the $p H$ Range. Thermal dependence of $k_{\text {cat }}$ was determined in the range 20$50^{\circ} \mathrm{C}$ and used to prepare Arrhenius (Supplemental Figure 4(a)) and Eyring (Supplemental Figure 4(b)) plots. The experiments were performed in $\mathrm{pH} 7.5$ and 11.0. The plots were linear in the experimental range. The thermodynamic parameters for the formation of the activated complex are given in Table 1 . The activation enthalpies are positive as reactions involving bond breakage are endothermic. The negative value of $\Delta S^{\ddagger}$ indicates that the reactants must assume precise conformation and approach each other at precise angle to form the transition state and that the molecules are constrained in the activated state. The positive value for $\Delta G^{\ddagger}$ was expected as the formation of transition state is nonspontaneous. Thus, the B. subtilis GGT catalysed hydrolytic reactions in $\mathrm{pH} 7.5$ and 11.0 are more or less thermodynamically similar, except for a small improvement in $\Delta S^{\ddagger}$ at $\mathrm{pH} 11.0$.

\section{Discussion}

The kinetics of GGT, particularly that of the mammalian homologues, have been extensively studied because of its physiological significance. Among microbial GGTs, the kinetics is mostly studied with the homologue from $E$. coli. Our detailed analysis of the enzymatic kinetics of $B$. subtilis GGT reveals interesting features that have so far been overlooked. Between pH 7.0 and 11.0, the $V_{\max }$ of hydrolysis progressively increased producing maximum activity at $\mathrm{pH}$ 11.0. This was contrary to the previously reported $\mathrm{pH}$ profile wherein the hydrolysis followed a bell-shaped curve with the maxima at $\mathrm{pH} 9.0$ [18]. Our analysis indicated that the reported optimum was an artifact as the $\mathrm{pH}$ profile was constructed not from $V_{\max }$ values but from comparative assays at fixed substrate concentration. The reported assays employed merely $1 \mathrm{mM}$ concentration of the substrate as the amount is the standard for most GGT assays, and, more importantly, the $K_{m}$ of $B$. subtilis GGT was unknown at that time. The lowered rates at $\mathrm{pH} 10.0$ and 11.0 relative to $\mathrm{pH}$ 9.0 under conditions of low substrate concentration were a consequence of kinetic transformation. At lower substrate concentrations, sigmoid kinetics typically produces slower rates than the corresponding hyperbolic form. We were able to recreate the bell-shaped curve by measuring the activities with $2 \mathrm{mM}$ substrate and contrast it with measurements made with $64 \mathrm{mM}$ substrate (Figure 1). The progressively increasing response at higher substrate concentration indicates the involvement of a critical acidic group that contributes to the catalysis in its deprotonated form.

The $\mathrm{pH}$ dependent transformation of the kinetics of substrate consumption from hyperbolic to sigmoid form is the most important observation in this study. From literature, we realised that a similar transitionary behaviour was observed previously in mammalian GGTs from human [25] and rabbit liver [22]. However, this aspect has not received much attention. The transition from hyperbolic to 
sigmoid form is sharp and occurs between pH 9.0 and 10.0. The kinetic data was analyzed using Hill's equation. This is a modification of Michaelis-Menten equation to account for multiple interacting binding sites. Hill's coefficient $(h)$ represents cooperativity between multiple $(n)$ binding sites. Hill's coefficient for hydrolysis in $\mathrm{pH} 10.0$ and $\mathrm{pH} 11.0$ was $>1$ indicating positive cooperativity between the interacting sites. The kinetic transformation is probably due to the involvement of a group with a $\mathrm{p} K_{a}$ of $\sim 9.5$, which upon deprotonation favours sigmoid kinetics. We need to explore if the critical deprotonated acidic group responsible for the maximal activity and the kinetic transformation are from the same amino acid residue.

Sigmoid curve is generally a feature of enzymes with multiple substrate binding sites with dissimilar affinities. Binding of a substrate molecule at one of sites either improves or diminishes the binding affinity of the other sites. Multiple binding sites often arise due to oligomeric organization of the protein. Our size exclusion chromatography experiments under conditions of $\mathrm{pH} 7.5$ and 11.0 gave same molecular weight, thus excluding oligomerization as the potential basis for sigmoid kinetics. Furthermore, CD spectroscopy data indicates the absence of any major structural changes. These results show that sigmoid kinetics arises due to nonconformational reasons.

GGT employs nucleophilic substitution mechanism of catalysis with the $\mathrm{N}$-terminal threonine of the smaller subunit serving as the catalytic nucleophile [26]. The crystal structure of $B$. subtilis GGT in complex with glutamate has been determined [27]. The structure shows a glutamate residue bound at the catalytically competent active site. These facts show that there is only one active site in GGT including the B. subtilis homologue. The possibility of a second substrate molecule binding to the acceptor amine binding site is ruled out as sigmoid kinetics was evident in the transpeptidation reactions also (data to be published). The crystal structures of $B$. subtilis GGT have been determined both in the native and substrate conjugated forms [27]. The enzyme has a kidney shape with a groove on one side of the molecule. The active site, where the glutamate moiety of the substrate binds, occurs as a finger-shaped depression towards the middle of the groove. The region immediately outside of the active site does not show any large pockets that might bind to a glutamate residue. Therefore, it is unlikely that the sigmoid kinetics arises due to cooperative binding of multiple substrate molecules. Sigmoid kinetics due to monomeric enzyme with single substrate binding sites has been extensively studied in mammalian glucokinase. The sigmoid behaviour in glucokinase arises because of its occurrence in two interconvertible conformations with dissimilar affinities for the substrate [28]. Preequilibrium kinetics and nuclear magnetic resonance studies are necessary to elucidate the origins of sigmoid kinetics in $B$. subtilis GGT.

In conclusion, our study shows the drastic effect of $\mathrm{pH}$ on the hydrolytic kinetics of B. subtilis GGT. Our data rules out changes in substrate specificity, conformation, catalytic mechanism, and oligomeric state as the cause for the kinetic transformation.

\section{Conflict of Interests}

The authors declare that there is no conflict of interests regarding the publication of this paper.

\section{References}

[1] N. D. Rawlings, F. R. Morton, and A. J. Barrett, "MEROPS: the peptidase database," Nucleic Acids Research, vol. 34, pp. D270D272, 2006.

[2] C. A. Hinchman, H. Matsumoto, T. W. Simmons, and N. Ballatori, "Intrahepatic conversion of a glutathione conjugate to its mercapturic acid: metabolism of 1-chloro-2,4-dinitrobenzene in isolated perfused rat and guinea pig livers," The Journal of Biological Chemistry, vol. 266, no. 33, pp. 22179-22185, 1991.

[3] A. Meister, "On the enzymology of amino acid tansport," Science, vol. 180, no. 4081, pp. 33-39, 1973.

[4] M. Benlloch, A. Ortega, P. Ferrer et al., "Acceleration of glutathione efflux and inhibition of $\gamma$-glutamyltranspeptidase sensitize metastatic B16 melanoma cells to endothelium-induced cytotoxicity," The Journal of Biological Chemistry, vol. 280, no. 8, pp. 6950-6959, 2005.

[5] A. Pompella, V. de Tata, A. Paolicchi, and F. Zunino, "Expression of $\gamma$-glutamyltransferase in cancer cells and its significance in drug resistance," Biochemical Pharmacology, vol. 71, no. 3, pp. 231-238, 2006

[6] Y. Hashimoto, A. Futamura, H. Nakarai, and K. Nakahara, "Blood pressure, levels of serum lipids, liver enzymes and blood glucose by aldehyde dehydrogenase 2 and drinking habit in Japanese men," Atherosclerosis, vol. 158, no. 2, pp. 465-470, 2001.

[7] J. Singh, J. Chander, S. Singh, G. Singh, and C. K. Atal, " $\gamma$-Glutamyl transpeptidase: a novel biochemical marker in inflammation," Biochemical Pharmacology, vol. 35, no. 21, pp. 3753-3760, 1986.

[8] D. H. Lee, M. H. Ha, J. H. Kim et al., " $\gamma$-glutamyltransferase and diabetes-a 4 year follow-up study," Diabetologia, vol. 46, no. 3 , pp. 359-364, 2003.

[9] J. Sian, D. T. Dexter, A. J. Lees, S. Daniel, P. Jenner, and C. D. Marsden, "Glutathione-related enzymes in brain in Parkinson's disease," Annals of Neurology, vol. 36, no. 3, pp. 356-361, 1994.

[10] M. N. Martin and J. P. Slovin, "Purified $\gamma$-glutamyl transpeptidases from tomato exhibit high affinity for glutathione and glutathione S-conjugates," Plant Physiology, vol. 122, no. 4, pp. 1417-1426, 2000.

[11] K. Kimura, L. P. Tran, I. Uchida, and Y. Itoh, "Characterization of Bacillus subtilis $\gamma$-glutamyltransferase and its involvement in the degradation of capsule poly- $\gamma$-glutamate," Microbiology, vol. 150, no. 12, pp. 4115-4123, 2004.

[12] T. Candela and A. Fouet, "Bacillus anthracis CapD, belonging to the $\gamma$-glutamyltranspeptidase family, is required for the covalent anchoring of capsule to peptidoglycan," Molecular Microbiology, vol. 57, no. 3, pp. 717-726, 2005.

[13] C. Chevalier, J. Thiberge, R. L. Ferrero, and A. Labigne, "Essential role of Helicobacter pylori $\gamma$-glutamyltranspeptidase for the colonization of the gastric mucosa of mice," Molecular Microbiology, vol. 31, no. 5, pp. 1359-1372, 1999.

[14] H. Takahashi, K. Hirose, and H. Watanabe, "Necessity of meningococcal $\gamma$-glutamyl aminopeptidase for Neisseria meningitidis growth in rat cerebrospinal fluid (CSF) and CSF-like medium," Journal of Bacteriology, vol. 186, no. 1, pp. 244-247, 2004. 
[15] B. Sharath, A. A. Prabhune, C. G. Suresh, A. J. Wilkinson, and J. A. Brannigan, "Crystal structure of $\gamma$ glutamyl transferase from Bacillus subtilis," Protein Data Bank Accession no. 2v36.

[16] H. Suzuki, H. Kumagai, and T. Tochikura, " $\gamma$-Glutamyltranspeptidase from Escherichia coli K-12: purification and properties," Journal of Bacteriology, vol. 168, no. 3, pp. 1325-1331, 1986.

[17] T. Okada, H. Suzuki, K. Wada, H. Kumagai, and K. Fukuyama, "Crystal structure of the $\gamma$-glutamyltranspeptidase precursor protein from Escherichia coli: structural changes upon autocatalytic processing and implications for the maturation mechanism," The Journal of Biological Chemistry, vol. 282, no. 4, pp. 2433-2439, 2007.

[18] H. Minami, H. Suzuki, and H. Kumagai, "A mutant Bacillus subtilis $\gamma$-glutamyltranspeptidase specialized in hydrolysis activity," FEMS Microbiology Letters, vol. 224, no. 2, pp. 169-173, 2003.

[19] G. Boanca, A. Sand, T. Okada et al., "Autoprocessing of Helicobacter pylori $\gamma$-glutamyltranspeptidase leads to the formation of a threonine-threonine catalytic dyad," The Journal of Biological Chemistry, vol. 282, no. 1, pp. 534-541, 2007.

[20] Y. Ikeda, J. Fujii, M. E. Anderson, N. Taniguchi, and A. Meister, "Involvement of Ser-451 and Ser-452 in the catalysis of human $\gamma$-glutamyl transpeptidase," The Journal of Biological Chemistry, vol. 270, no. 38, pp. 22223-22228, 1995.

[21] J. S. Elce and B. Broxmeyer, " $\gamma$ Glutamyltransferase of rat kidney. Simultaneous assay of the hydrolysis and transfer reactions with (glutamate 14C)glutathione," Biochemical Journal, vol. 153, no. 2, pp. 223-232, 1976.

[22] D. Bagrel, C. Petitclerc, F. Schiele, and G. Siest, "Some kinetic properties of $\gamma$-glutamyltransferase from rabbi liver," Biochimica et Biophysica Acta, vol. 658, no. 2, pp. 220-231, 1981.

[23] J. W. London, L. M. Shaw, D. Fetterolf, and D. Garfinkel, "Determination of the mechanism and kinetic constants for hog kidney $\gamma$ glutamyltransferase," Biochemical Journal, vol. 157, no. 3, pp. 609-617, 1976.

[24] S. M. Kelly and N. C. Price, "The use of circular dichroism in the investigation of protein structure and function," Current Protein and Peptide Science, vol. 1, no. 4, pp. 349-384, 2000.

[25] C. PetitClerc, F. Schiele, D. Bagrel, A. Mahassen, and G. Siest, "Kinetic properties of $\gamma$-glutamyltransferase from human liver," Clinical Chemistry, vol. 26, no. 12, pp. 1688-1693, 1980.

[26] J. W. Keillor, R. Castonguay, and C. Lherbet, " $\gamma$-glutamyl transpeptidase substrate specificity and catalytic mechanism," Methods in Enzymology, vol. 401, pp. 449-467, 2005.

[27] K. Wada, M. Irie, H. Suzuki, and K. Fukuyama, "Crystal structure of the halotolerant $\gamma$-glutamyltranspeptidase from Bacillus subtilis in complex with glutamate reveals a unique architecture of the solvent-exposed catalytic pocket," FEBS Journal, vol. 277, no. 4, pp. 1000-1009, 2010.

[28] M. Larion and B. G. Miller, "Homotropic allosteric regulation in monomeric mammalian glucokinase," Archives of Biochemistry and Biophysics, vol. 519, no. 2, pp. 103-111, 2012. 

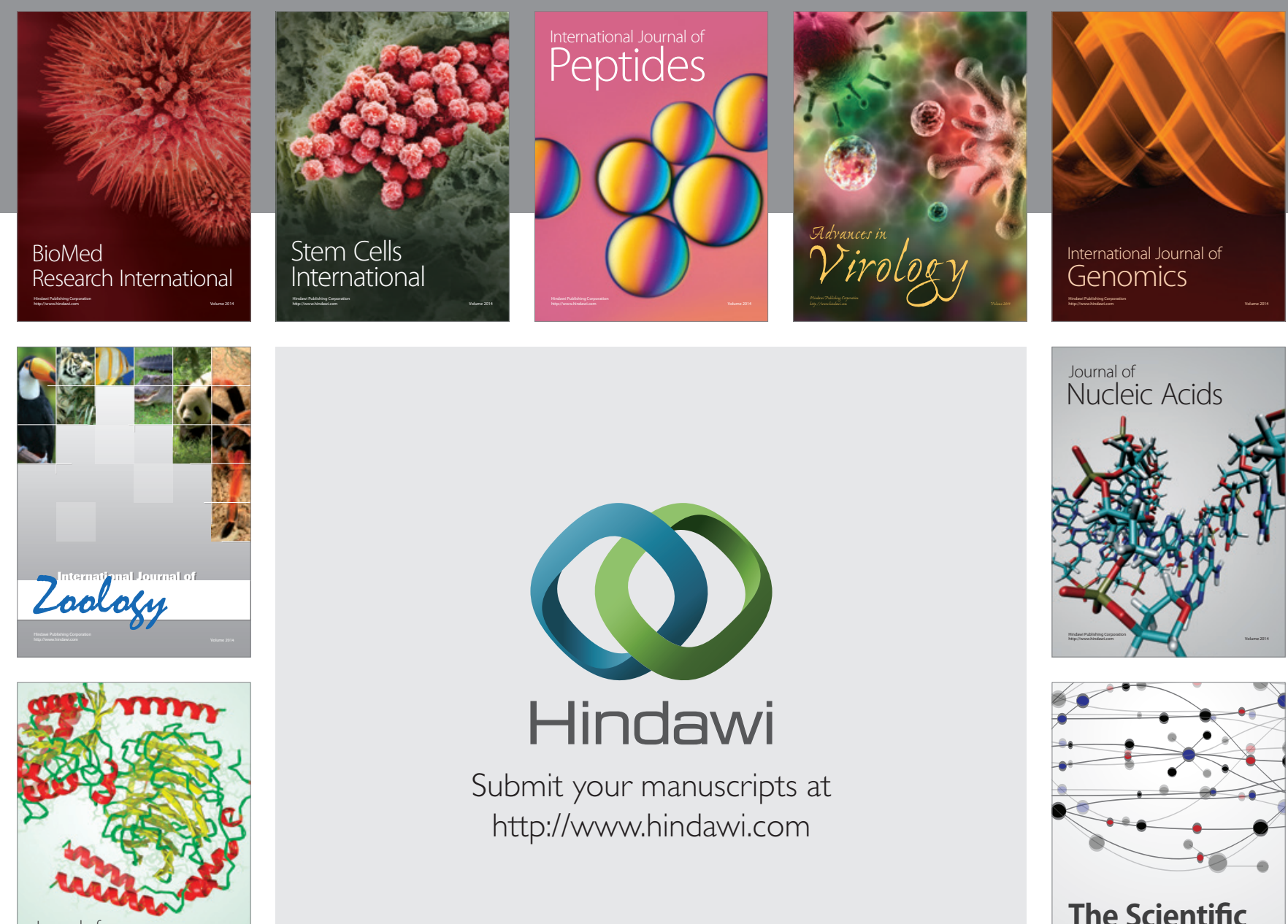

Submit your manuscripts at

http://www.hindawi.com

Journal of
Signal Transduction
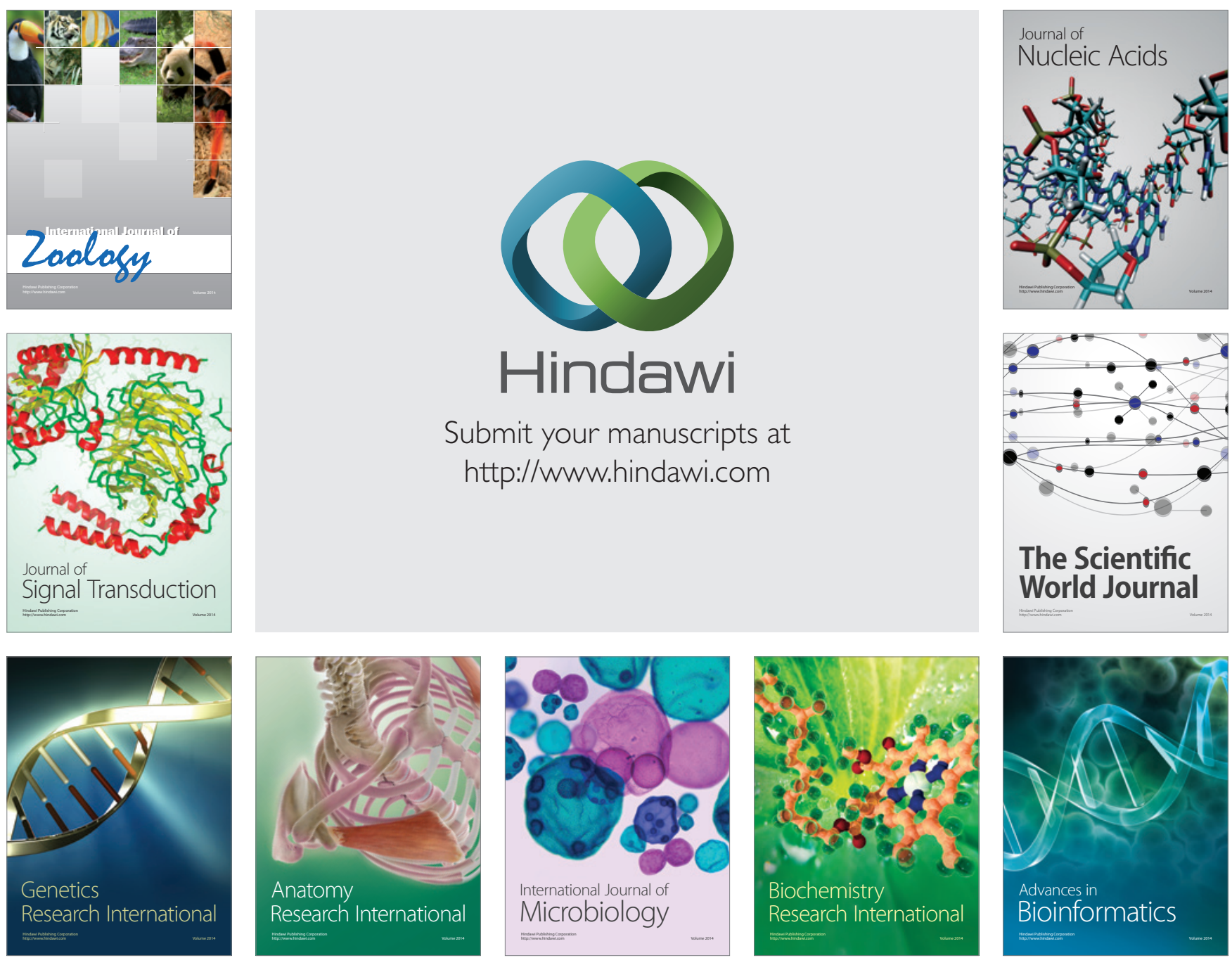

The Scientific World Journal
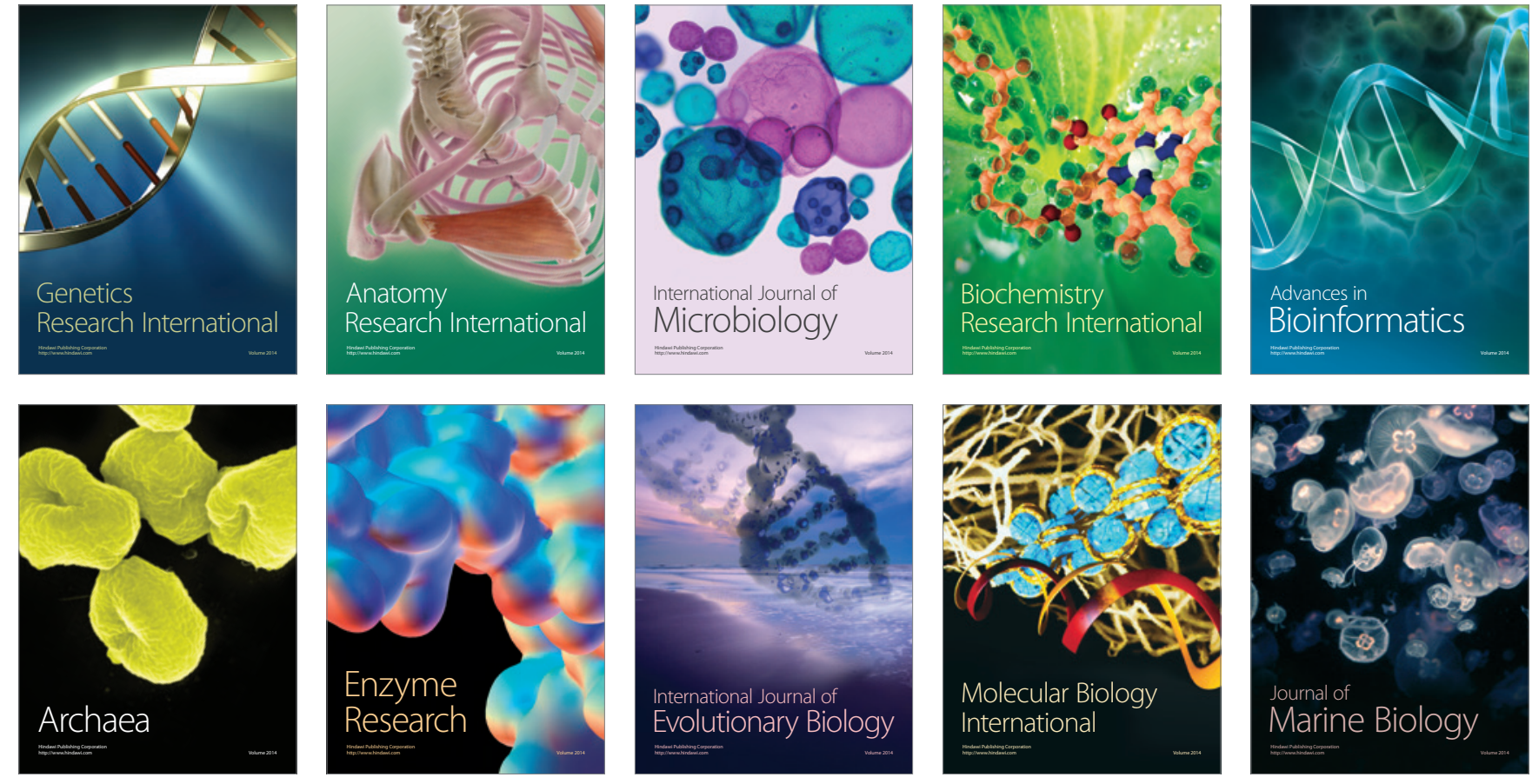